\title{
ظاهرة التطرف الديني في المجتمعات العربية: دراسة تحليلية
}

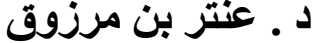 \\ كلية الحقوق و العلوم السياسية

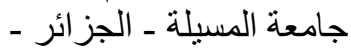

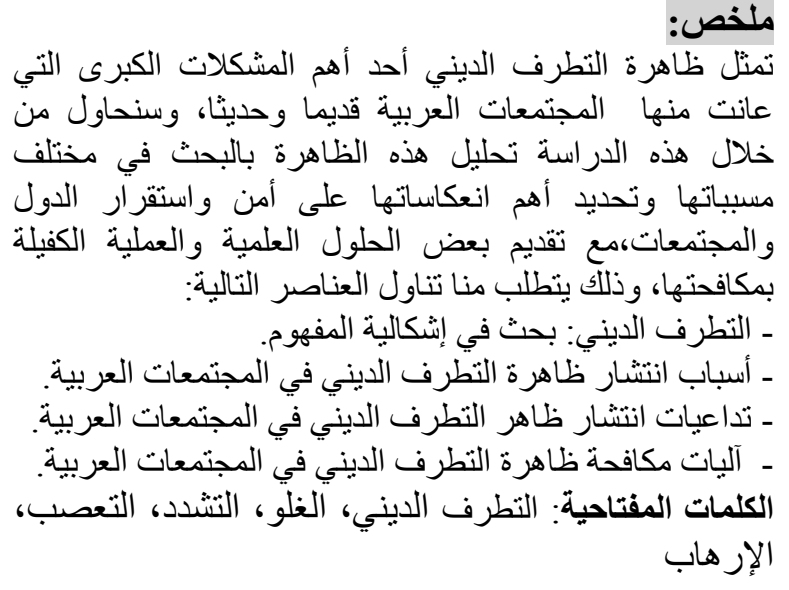

ملخص:

تمثل ظاهرة النطرف الديني أحد أهم المشكلات الكبرى التي

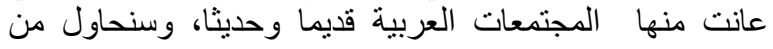

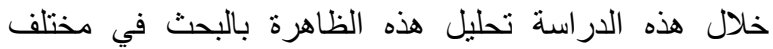

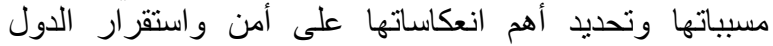

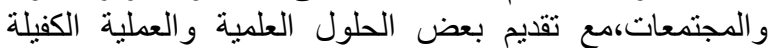
بمكافحتها، وذللك يتطلب منا تتاول العناصر التالية: ـ ـ التطرف الديني: بحث في إنكالية المفهوم.

ـ ـ أسباب انتشار ظاهرة التطرف الديني في المجتمعات العربية.

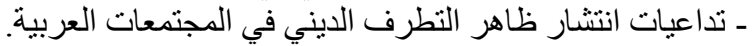

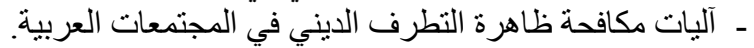

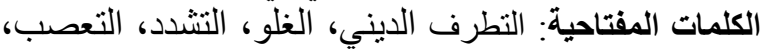

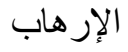

\section{Résumé}

رغم أن ظاهرة التطرف الديني ظاهرة

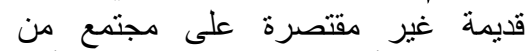

المجتمعات أو دين من الديانات، إلإ أنها

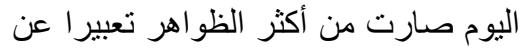

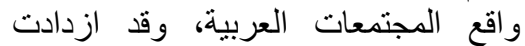

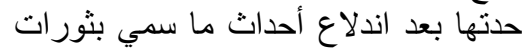

الربيع العربي، فقد عملت التحولات التهات الجديدة

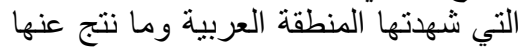

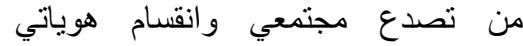

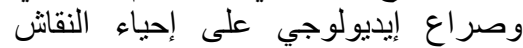

حول ظاهرة التطرف وطبيعتها وعلاعتهاه

بالدين، مما دفع بالعديد من البالباحثين

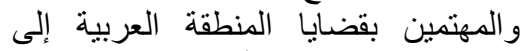

دراستها والبحث عن أسبابها و آليات الحد الى الى

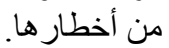

Le phénomène de l'extrémisme religieux est l'un des principaux problèmes rencontrés par les sociétés arabes, anciennes et récentes, et à travers cette étude, nous allons essayer d'analyser ce phénomène en examinant ses diverses causes et en identifiant ses implications les plus importantes pour la sécurité et la stabilité des États et des sociétés, en proposant des solutions scientifiques et pratiques Pour le combattre, ce qui nous oblige à aborder les éléments suivants:

-extrémisme religieux: recherche sur le problème du concept.

-les causes de la propagation de l'extrémisme religieux dans les sociétés arabes.

-les répercussions de la propagation de l'extrémisme religieux dans les sociétés arabes.

-les mécanismes de lutte contre le phénomène de l'extrémisme religieux dans les sociétés arabes. 
هذه الدراسة ستحاول الإجابة عن الإثكالية المتعلقة بالبحث عن مختلف العو امل المساهمة في انتشار

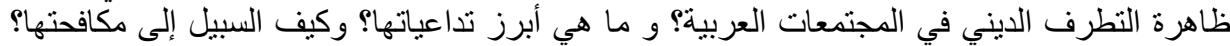

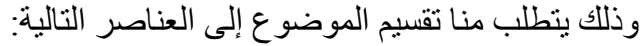
-

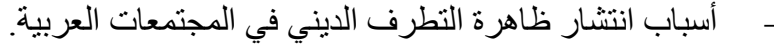

- _ - ـداعيات انتشار ظاهر التطرف الديني في المجتمعات العربية.

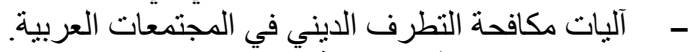

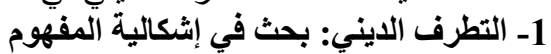

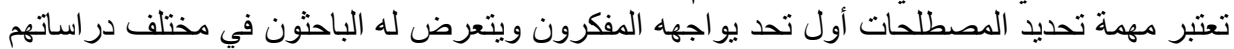

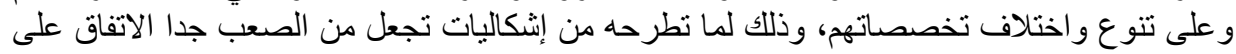

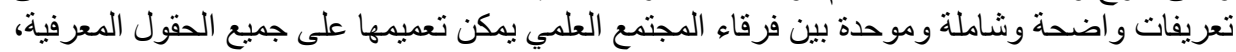
ويعتبر مصطلح التطرف الديني واحدا من هذه المصنط فيلحات التي تعرف تعددا في التعريفات المقدمة لها. أـ التطرف الايني لغة: النغ

التطّرف لغة من الفعل تطرف بمعنى أتى الطرف، ويقال: تطرفت الثمس دنت إلى الغروب، ويقال

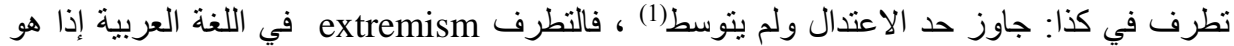

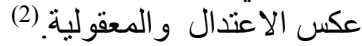

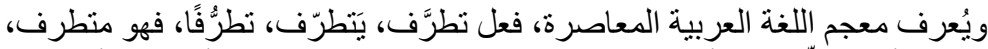

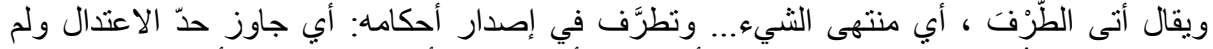

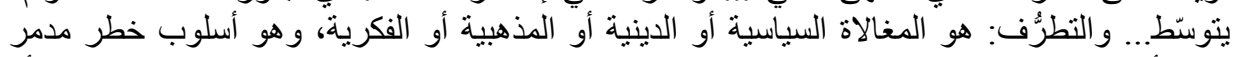

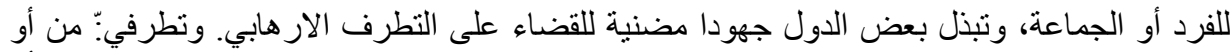

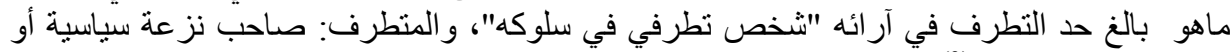

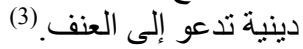
ويشير الثيخ القرضاوي في كتابه الصحوة الإسلامية بين الجمود و التطرف أن التطرف لغنة معناه التطاه

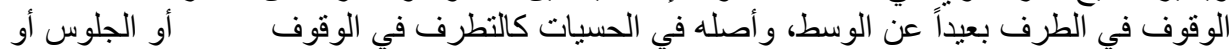

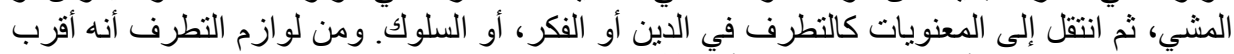

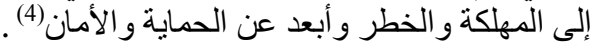

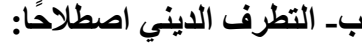

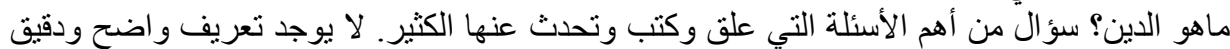

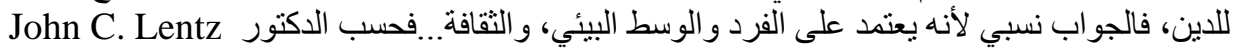

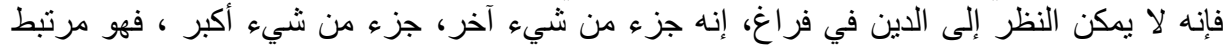

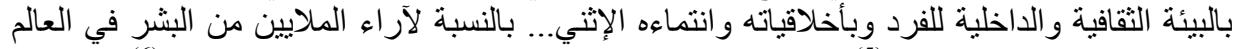

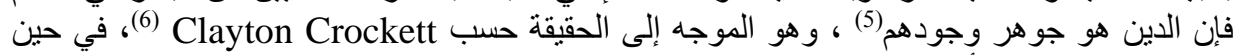

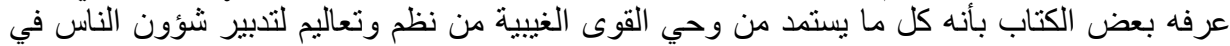

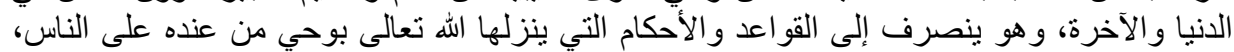

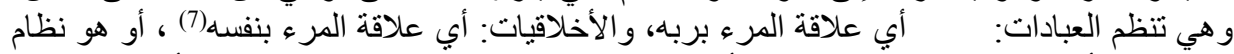

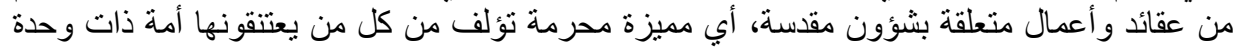

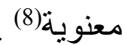

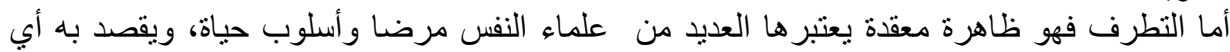
أبديولوجية أو قانون سياسي يكون خارج مركز السيرة الياسية المتصورة للمجتمع، و يهدف الى الى انتهاك

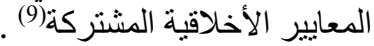

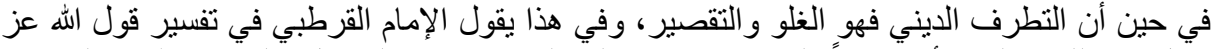

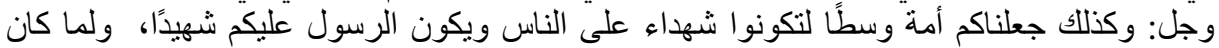


الوسط مجانبا للغلو و التقصير كان محمودًا، أب هذه الأمة لم تَغْلُ غلو النصارى في أنبيائهم و لا قصروا تقصير اليهود في أنبيائهم (10).

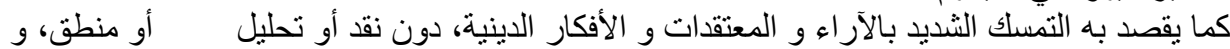

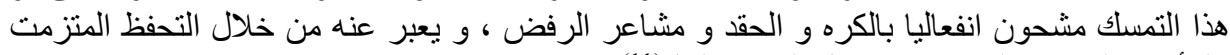

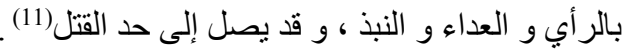

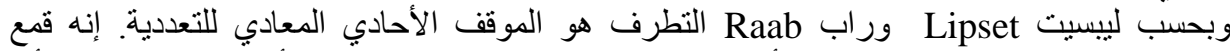

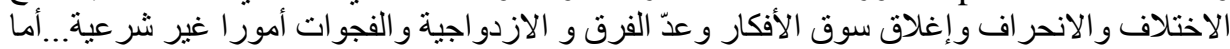

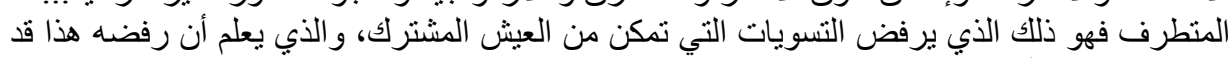

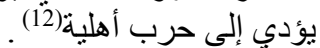

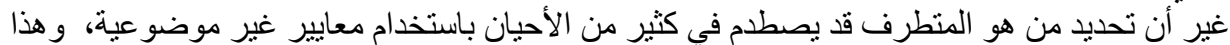

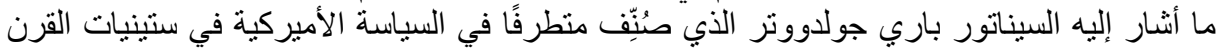

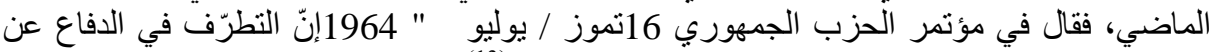

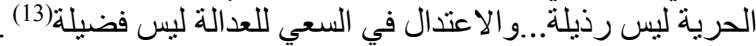

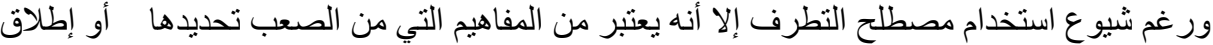

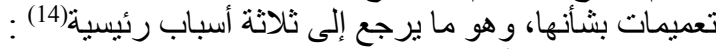

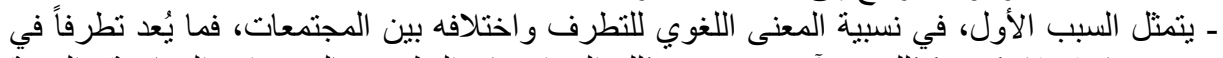

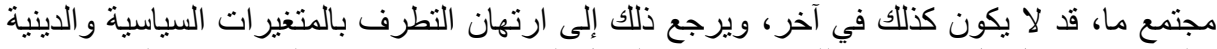
و الحضارية داخل كل مجتمع كذللك فإنه يرتبط بالعامل الزمني، حيث يتفاوت التطرن التطرف في المجتمع نفسه

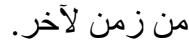
- وينصرف السبب الثاني، إلى ارتباط ظاهرة التطرف بالكثير من العلوم الإنسانية كعلم النفس وعلم

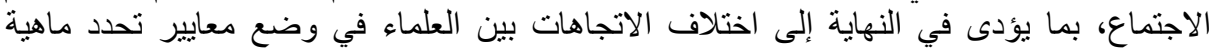

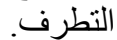
- ويتعلق السبب الثالث، بالخطأ الذي يقع فيه البعض باستخدام مفاهيم أخرى كمرادفات لهصطلح

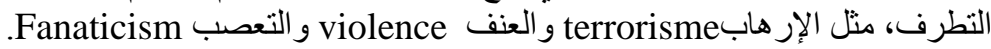
ج- التطرف الايني وبعض الإن المفاهيم المشابهة:

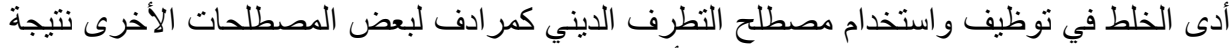

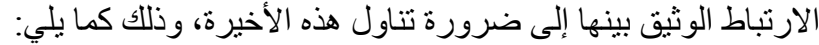

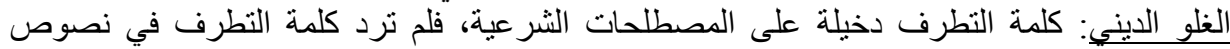

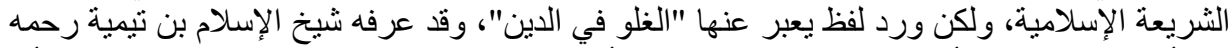

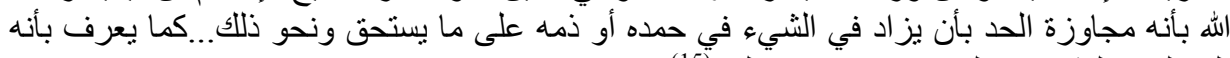

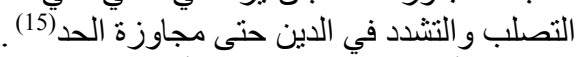

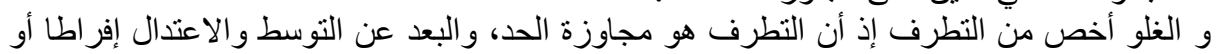

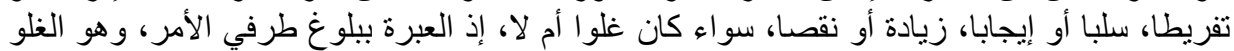

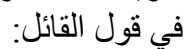

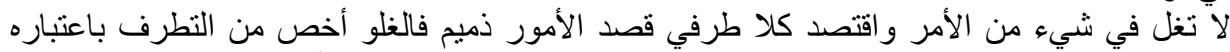

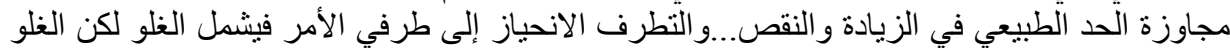

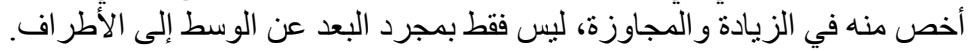

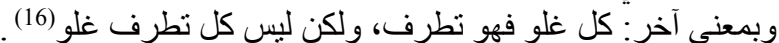

التثدد: التثدد أحد صور الغلو والتطرف، أو السمة التي يمكن اكتثافها لمعرفة درجة الغلو أو التطرف

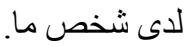

ويثير مفهوم التثدد من المنظور الديني التثديد على النفس أن يكلفها من العبادة فوق طاقتها. وهو اخص من الغلو. لأنه يتعلق بالعبادة العطلية، بخلاف الغلو ، فإنه يتعلق بالعبادات و العقائد. كما أن المتثدد وهائ 
نفسه قد لا يتعدى ما حده الله كما في الغلو، و على ذللك فإن معنى التثدد الديني هو ما برتبط بممارسات

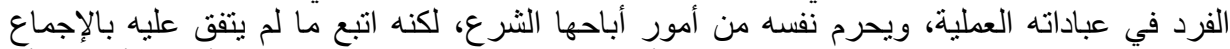

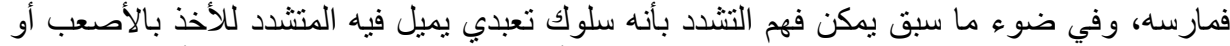

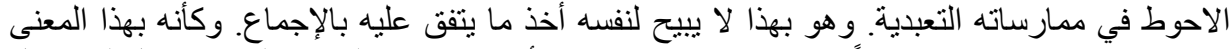

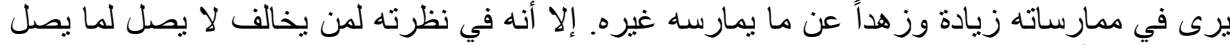

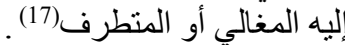

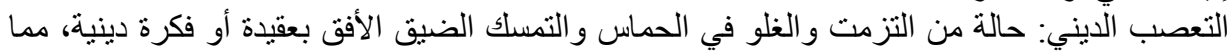

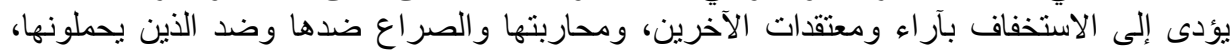

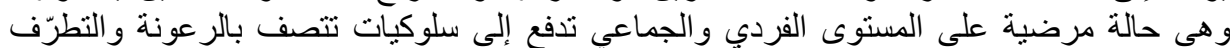

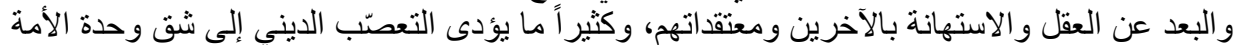

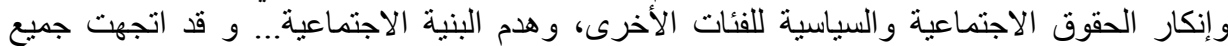

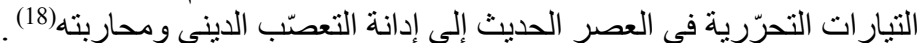

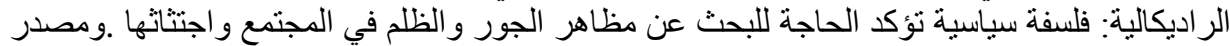

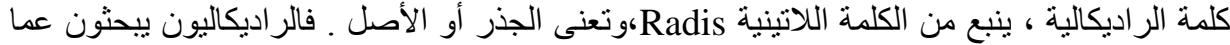
يعتبرونه جذور الأخطاء الاقتصادية والسياسية والاجتماعية في المجتمع ويطالبون بالتغييرات الإنيات الفورية

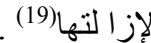

الإرهاب: من الصعب جدا تحديد تعريف دقيق لمصطلح الإرهاب في زمن اختلطت فيه المفاهيم بعد أن ونان

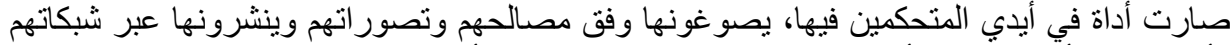

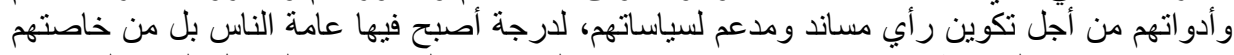

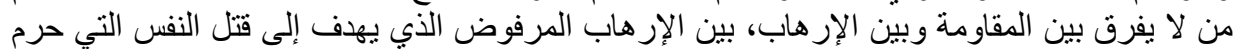

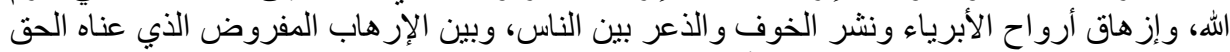

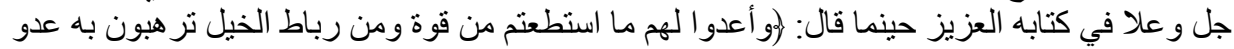

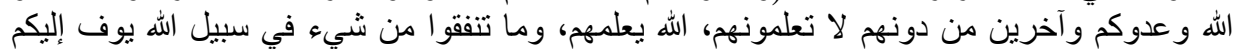

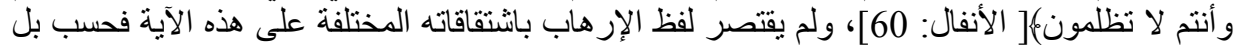

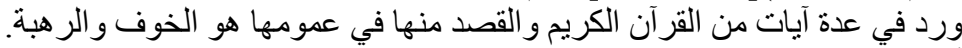

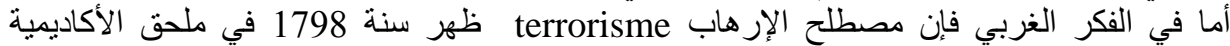

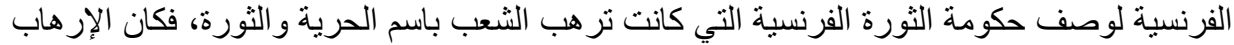

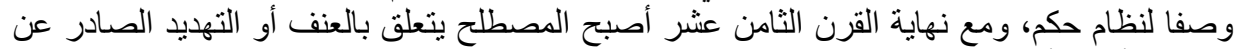

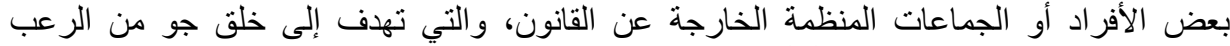
و الخوف والذعر و الفزع بين الناس(20). و عموما فإن مفهوم التطرف الديني يحمل في معانيه الغلو والتثند و التنطع و التزمت و التصلب و وغير

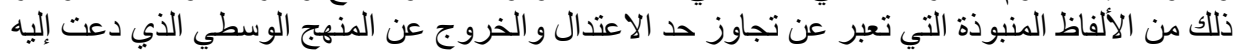

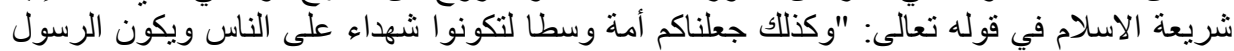
عليكم شهيدا". (الآية 143 من سورة البهابل البقرة). 2- أسباب انتثار ظاهرة التطرف الديني في الدئ المجتمعات العربية

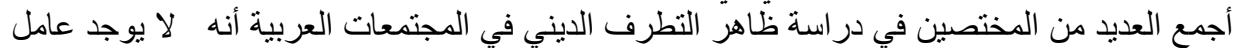

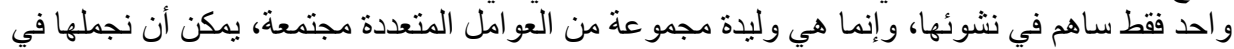

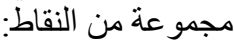
ـ العامل الخارجي وصناعة التطرف الديني: رغم إهمال العديد من الباحثين لتأثير العامل الخارجي في التاني

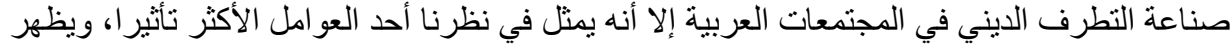

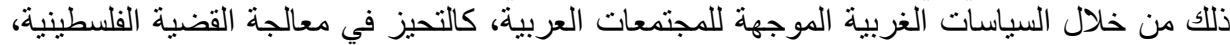


ومحاربة القيم الإسلامية واستبدالها بالقيم العلمانية سياسة وتثريعا وتعليما، وتدعيم الأنظمة التسلطية،

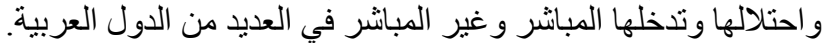

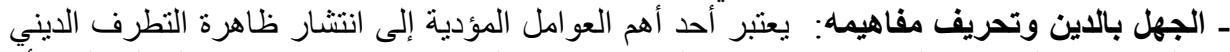

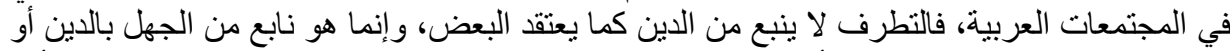

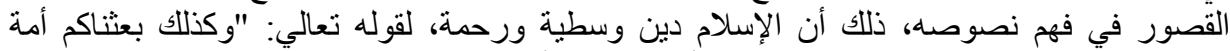
وسطا" (الآية 143 من سورة البقرة) وقوله أيضا: "وما أرسلناك إلا رحمة للعالمين."( الآية 107 من الإك

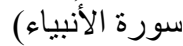
فالفهم الخاطئ للشريعة الإسلامية ومقاصدها السامية يمثل انحر افاً وتطرفا فكريا عن المنهج العقلي

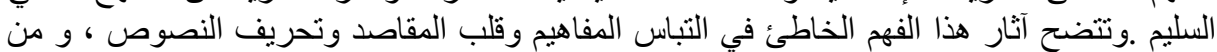

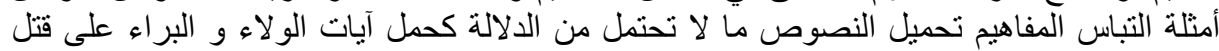

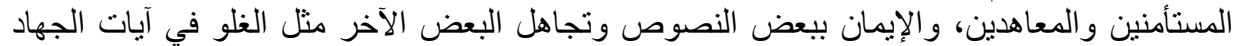

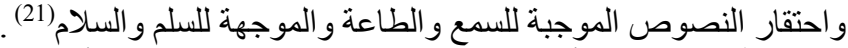

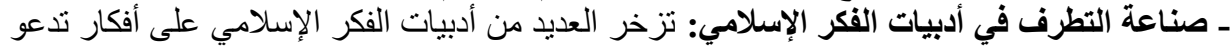

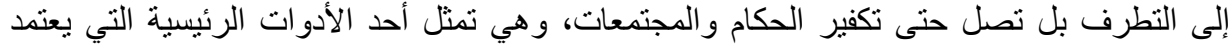

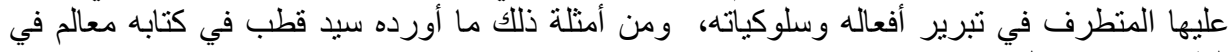

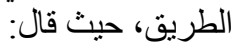

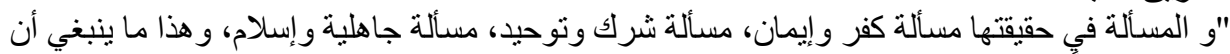

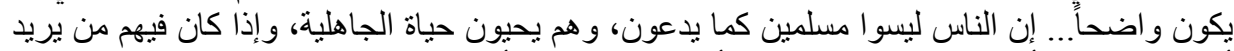

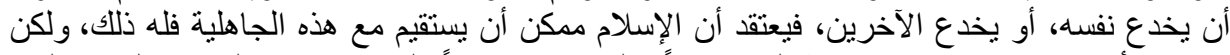

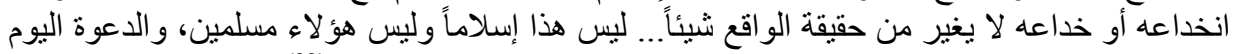

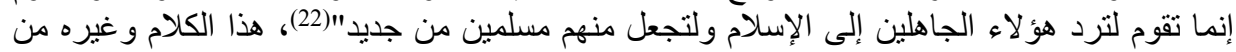

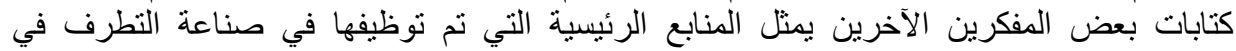

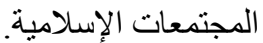

ومن المفاهيم الأكثر رواجا والتي كانت عرضة للانتقاد من طرف بعض رضان رواد الفكر الإسلامي وصلت

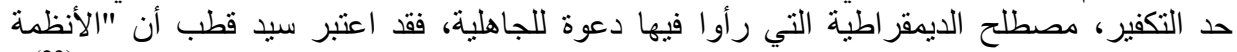

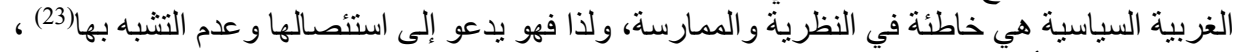

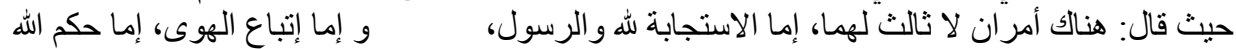

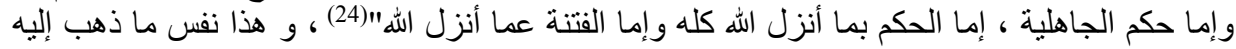

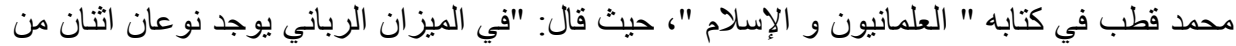

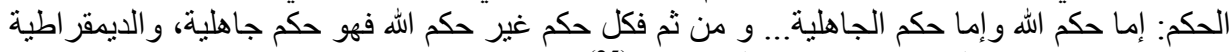
حيث إنها ليست حكم الله فهي في ميز الهان الله جاهلية" (25) .

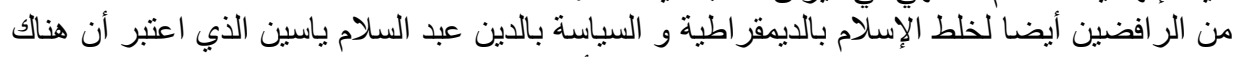

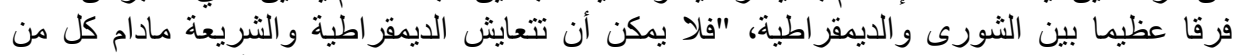

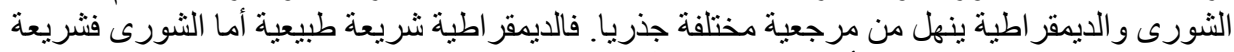

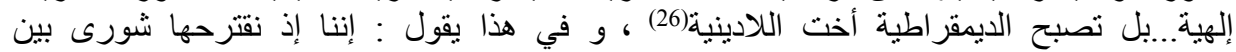

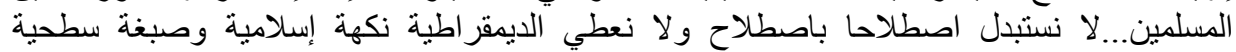

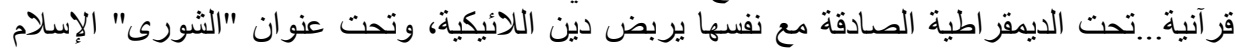

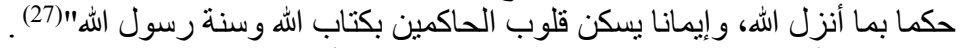

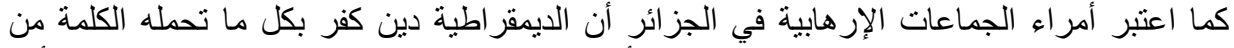

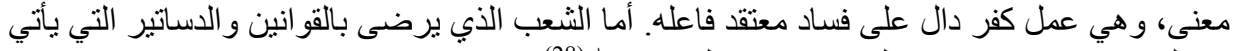

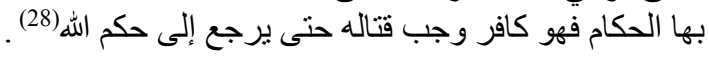


انطلاقا من كل هذا فإن التطرف و العنف والإرهاب هي ظو اهر قبل أن تتنقل إلى عالم الو اقع فهي وليدة

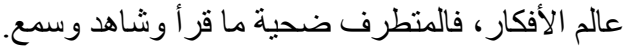

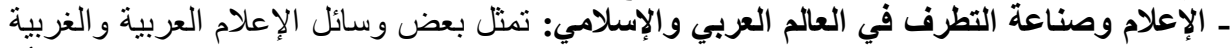

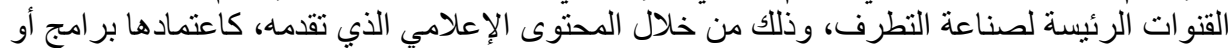

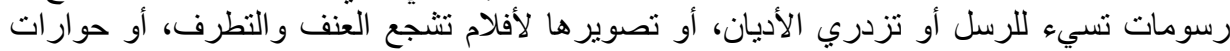

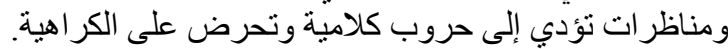

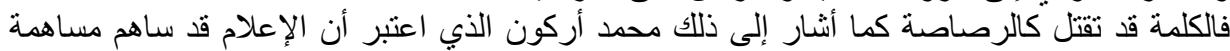
كبيرة في الصدام الموجود بين العالم العربي والإسلامي و العالم الغربي ، حيث الغي قال في كتابه "قضايا في

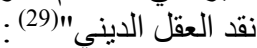

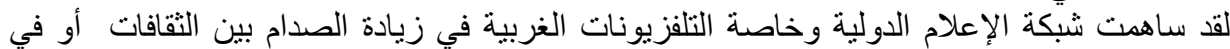

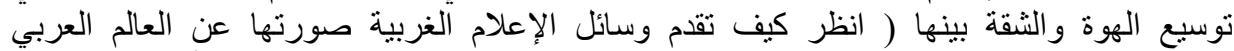

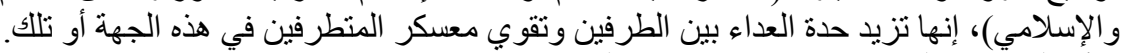

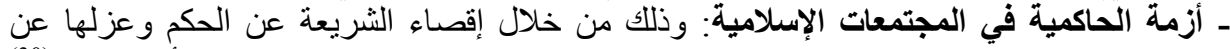

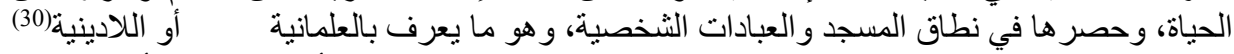

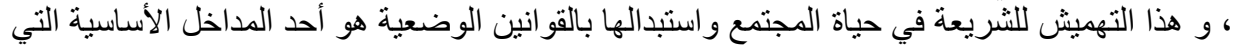

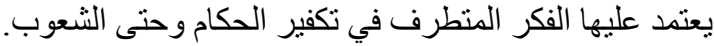

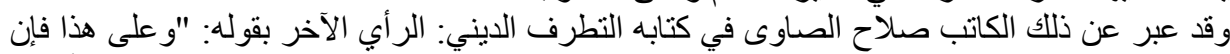

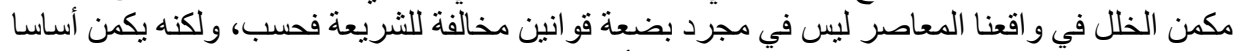

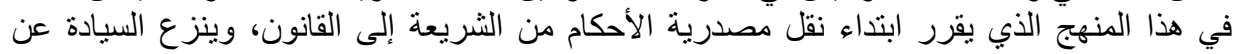

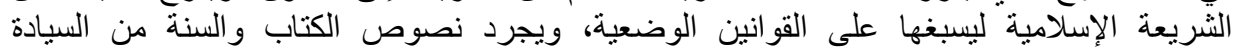

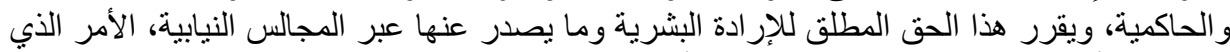

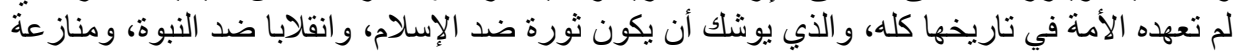

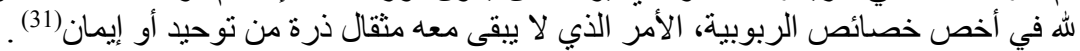

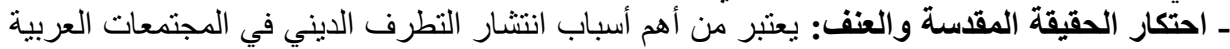

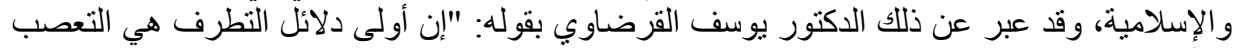

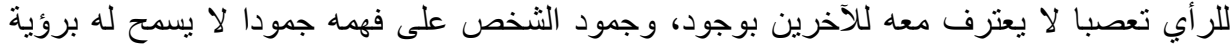

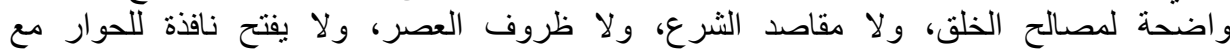

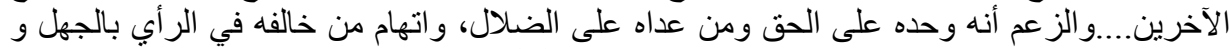

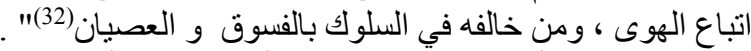

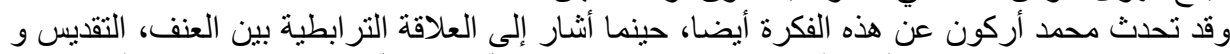

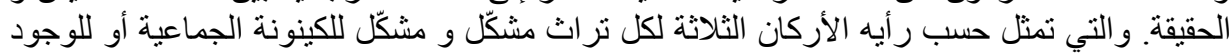

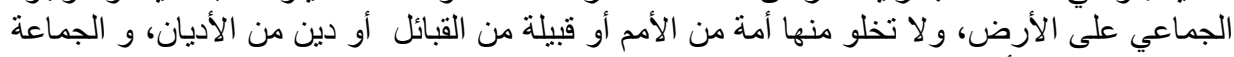

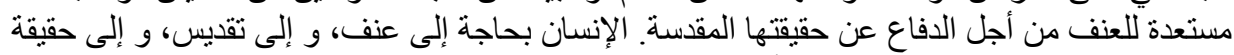

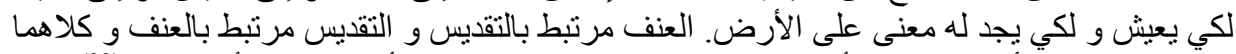

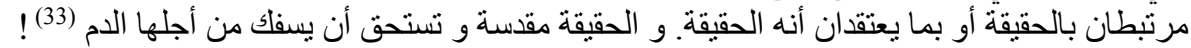

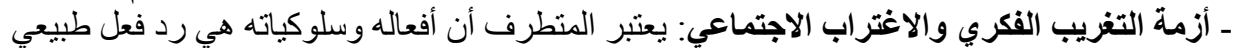

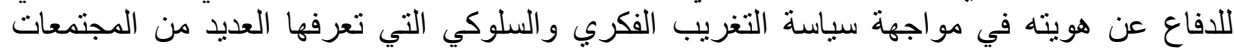

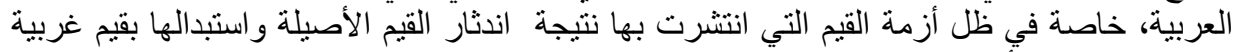

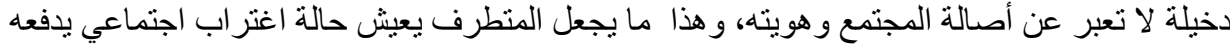

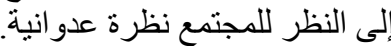

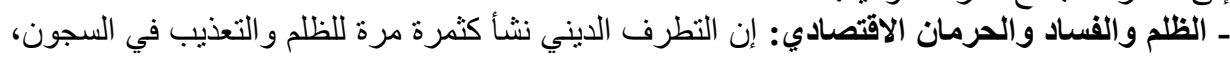

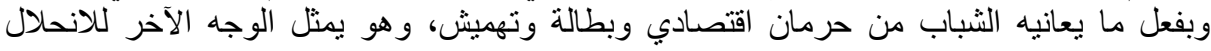




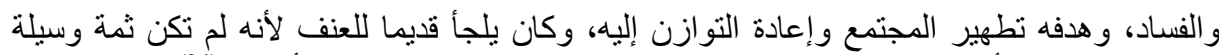

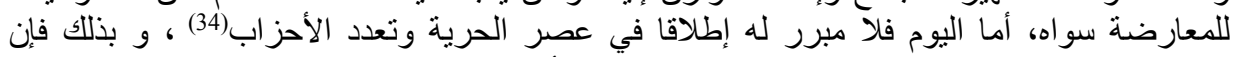

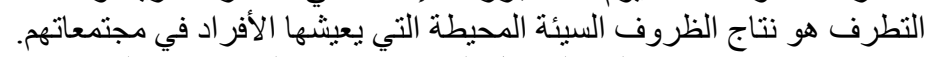

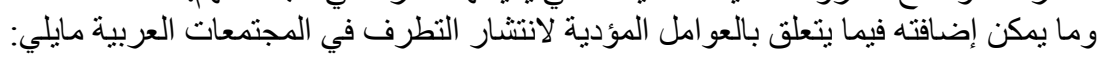

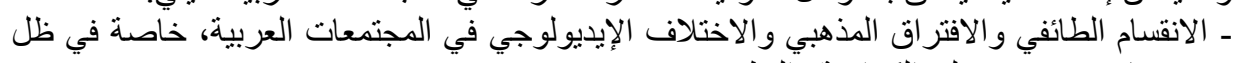

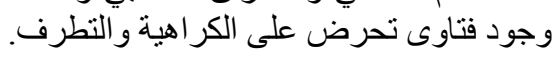

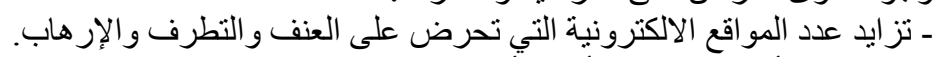

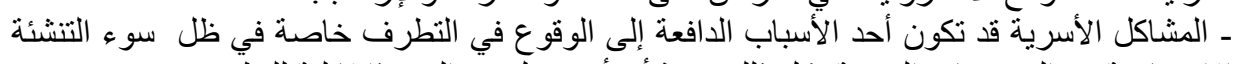

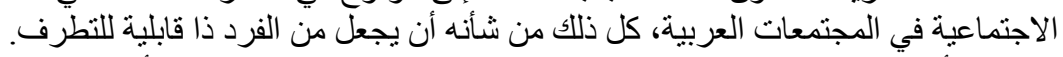

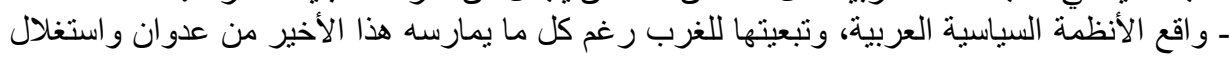

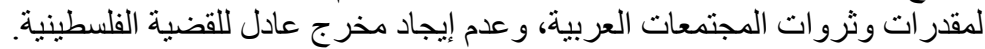

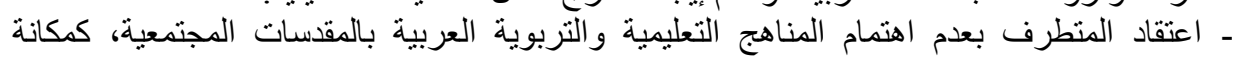

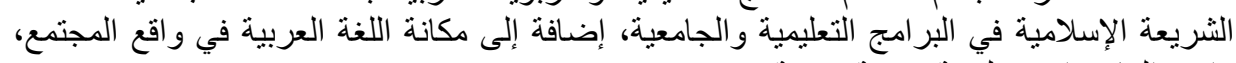
و واستبدالها ببر امج تعليمية غربية الإنية غريبة عنده.

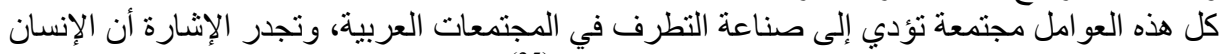

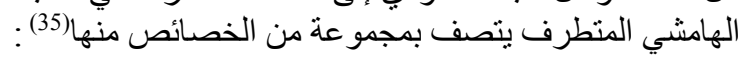

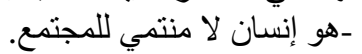
- يمتاز بسمات شخصية معادية لمجتمعها.

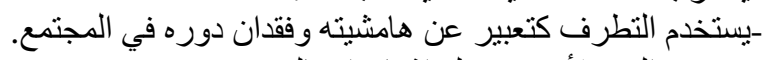

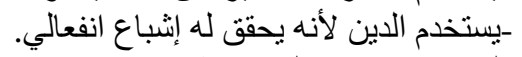

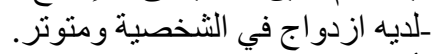
ـ أناني لا يقاو دو افع الفه الفردية.

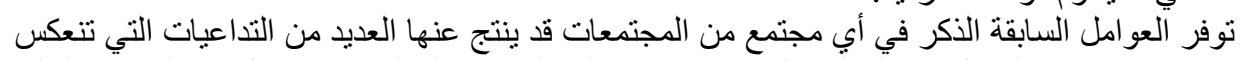

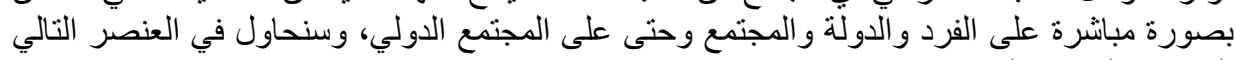
التعرف على هذه التداعيات.

3- تداعيات انتثار ظاهر التطرف الدايني في المجتمعات العربية

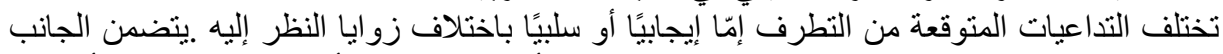

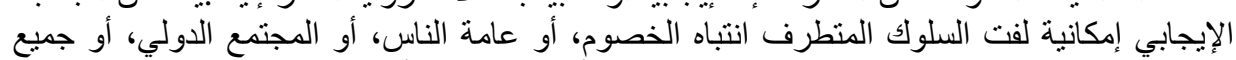

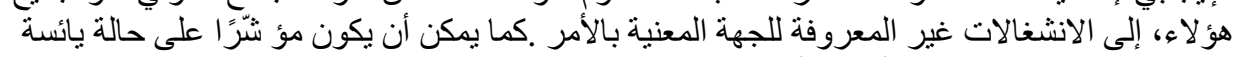

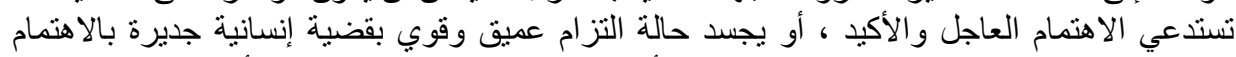

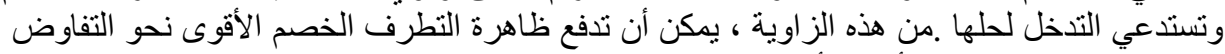

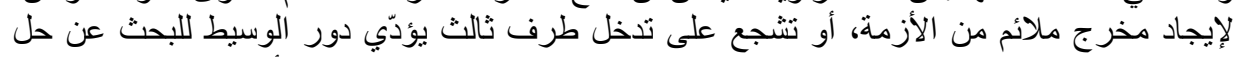

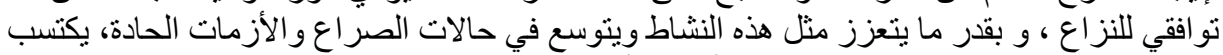

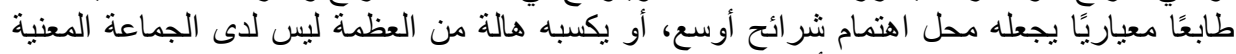

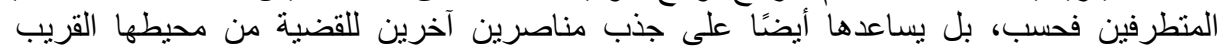
و البعيد(36). (النمين.

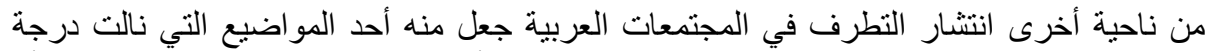

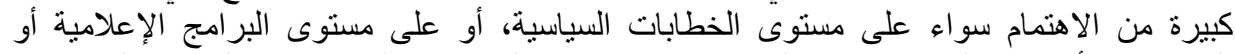

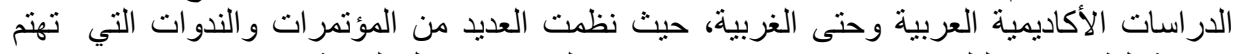

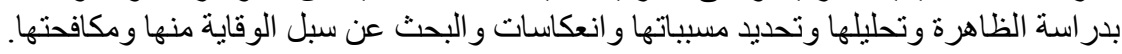


على الصعيد الاجتماعي دفع انتشار ظاهرة التطرف العديد من الدول العربية الى وضع سياسات

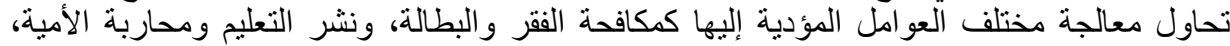

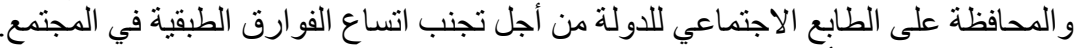

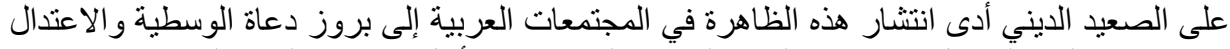

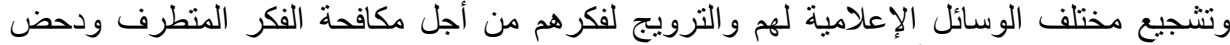

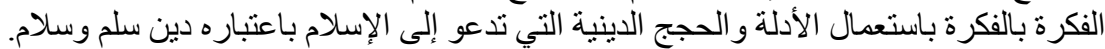

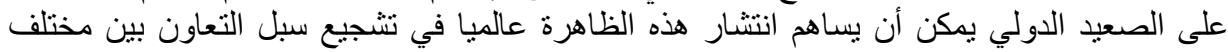

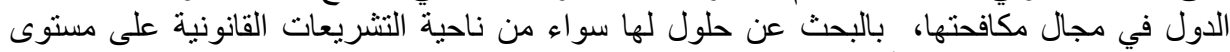

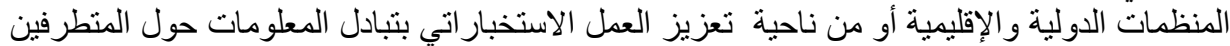

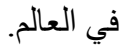

ورغم بعض التداعيات الايجابية التي يمكن أن بخلفها انتشار ظاهرة التطرف الديني في المجتمعات

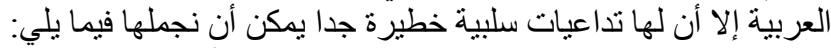

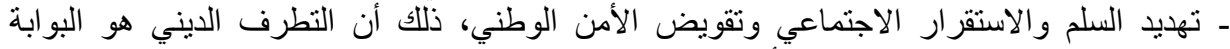

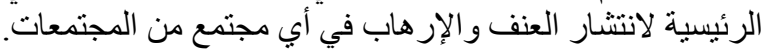

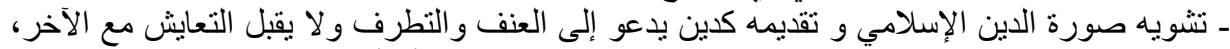

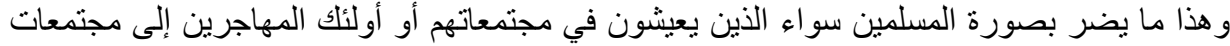

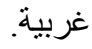
ـ التطرف الديني يؤدي إلى تفكك الأمة الإسلامية وتفرقها إلى شيع وطو ائف متناحرة، خاصة في ظل وجود فتاوى تشجع على ذلإلك وتدعو إليله ـ ـتشويه صورة البلد الذي تنتشر فيه ظارعرة الكيه التطرف الديني وما ينتج عن ذلك من تهديد للمقدرات

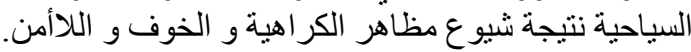

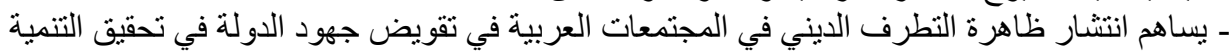

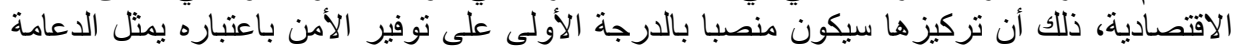

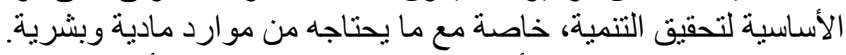

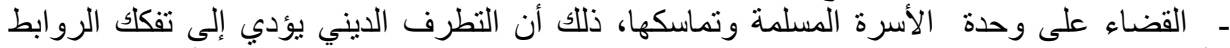

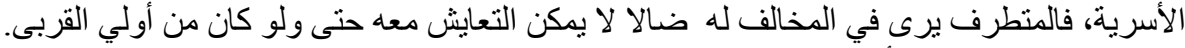

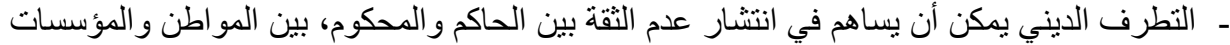

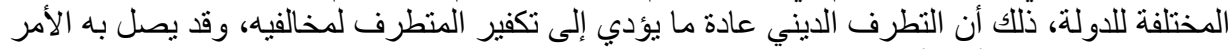

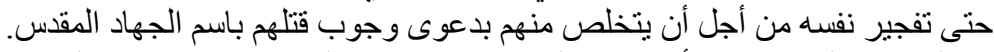

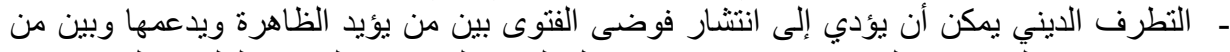

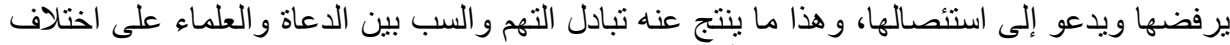

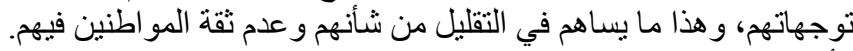

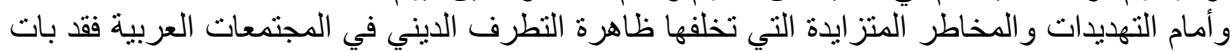
لز اما على مختلف الدول البحث عن آليات و ميكانيزمات يمكن من خلالاها التخفيف من حدة التهات التهديدات الناجمة عنها.

4- آليات مكافحة التطرف الايني في المجتمعات العربية:

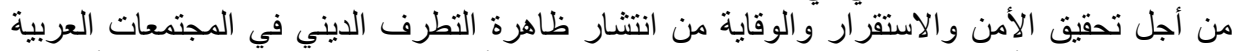

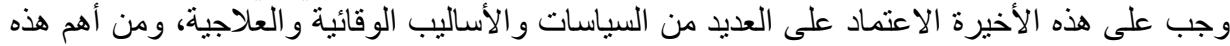

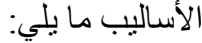

ـ اعتماد سياسة وقائية بنشر ثقافة السلم والأمن وزيادة الوعي المجتمعي بمختلف المخاطر و التهديدات التهات

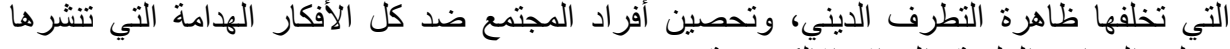
مختلف المر اجع العلمية والمو اقع الالكترونية. 
ـ تفعيل دور وسائل الإعلام في مواجهة الفكر المنطرف في المجتمعات العربية، والتحذير من مختلف

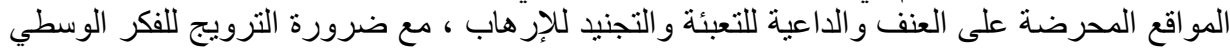

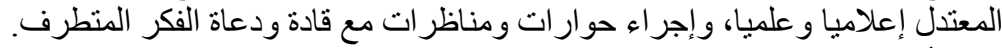

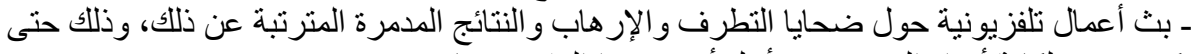

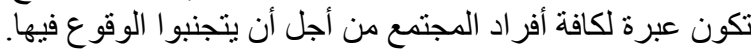

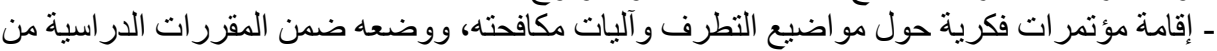

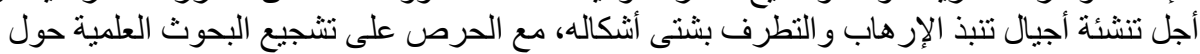
الظاهرة بما يؤدي إلى دحض هذال التها الفكر الخطير.

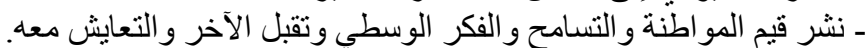

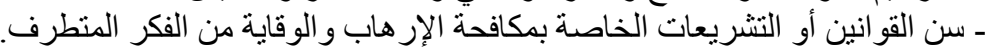

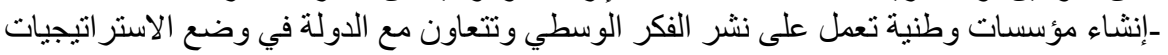

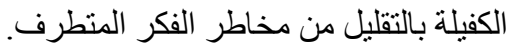
ـ التعاون الدولي في مجال دحض المنطرفين و اكتثافهم و الكثف عنهم وتبادل المعلومات بين الأجهزة الاستخبار اتية حولهم.

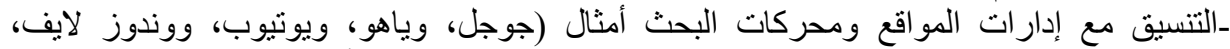

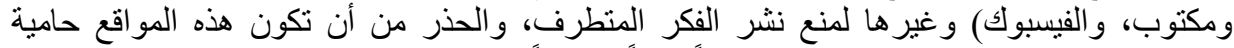

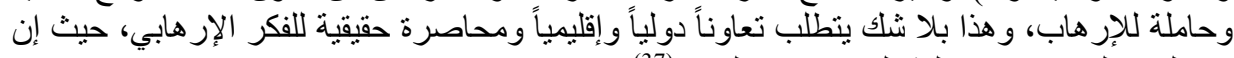

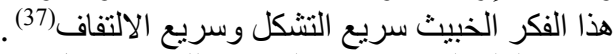

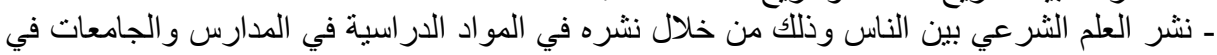

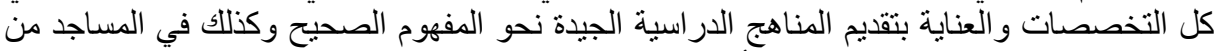

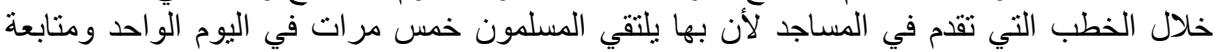

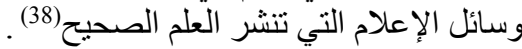

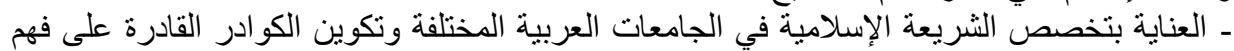

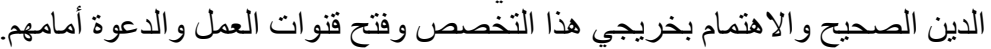

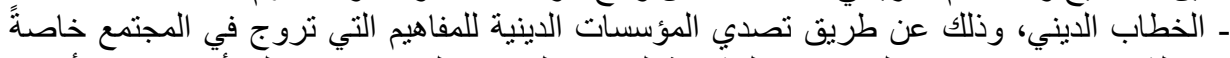

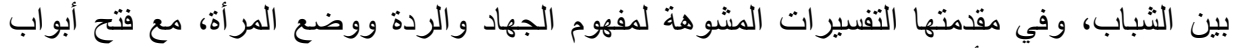

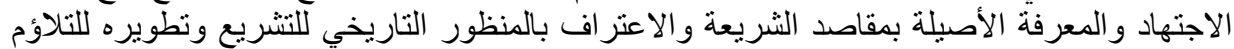

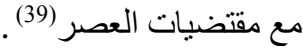

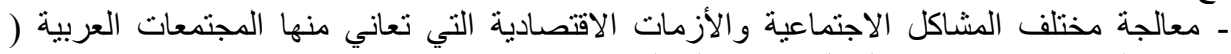

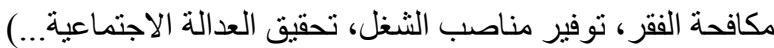

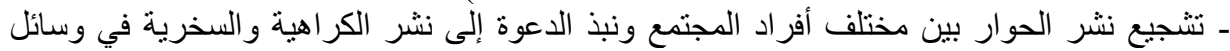

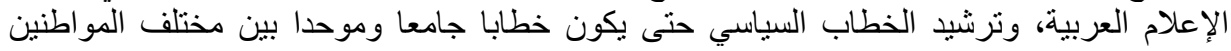
وليس خطابا إقصائيا مفرقا. ـ ـ احترام الدولة للإسلام والدفاع عنده في تشريعاتها التني يجب أن تستمد من الثريعة الإسلامية، وفي

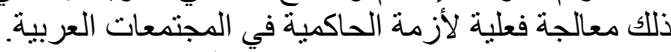

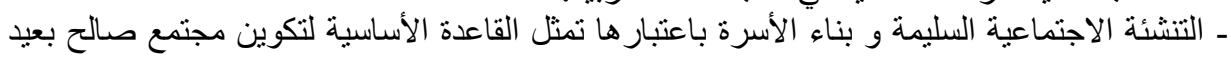

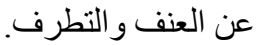
ـ ـ احتر ام العلماء وتوقير هم و عدم التقليل من شأنهم و أخذ العلم عنهم، وتبيان الحق منهم.

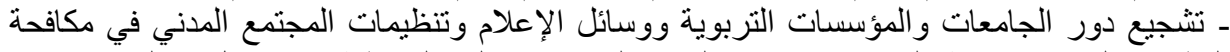

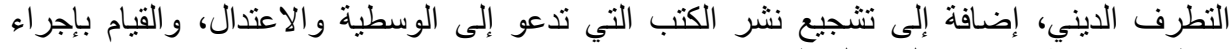
مناظر ات فكرية مع رواد الفكر المنطرف. 
ــ التحذير من الفتاوى والكتابات التي تثجع على التطرف والعنف، وخاصة تلاك التي تبيح تكفير المسلمين بغير وجه حق، لأن أصل التطرف الديني نابع من سوء فهم الدين ومن الفتاوى التي تدعو إلى لئ التكفير.

- وضع تثريعات قانونية فعالة يمكن أن تساهم في التقليل من حدة انتشار الظاهرة في المجتمعات

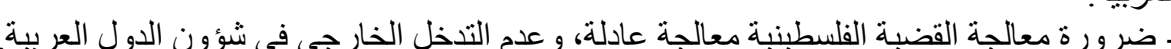

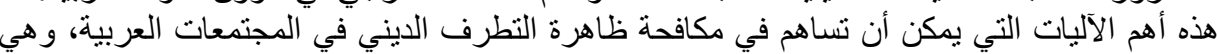

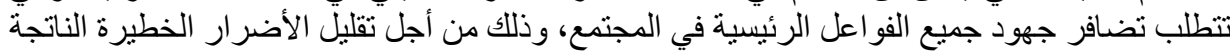

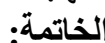
في الأخير و انطلاقا من كل ما سبق يمكن القول أن مسألة مكافحة التطرف الديني في المجتمعات العربية

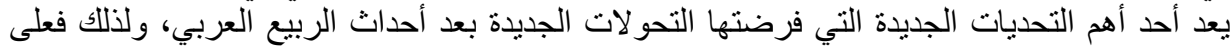

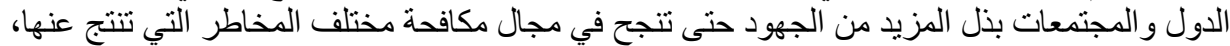
والتي يأتي على رأسها الإرهاب وغيره من التهايدات التي يمثل الانتصار عليها النتصار اللإنسانية جمعاء. ومن النتائج التي يمكن التوصل إليها بعد در اسة وتحليل هذه الظاهرة ما يلي:

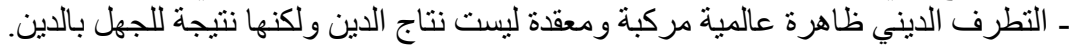

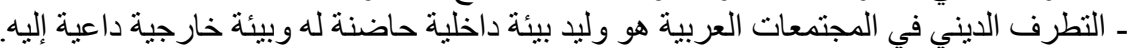

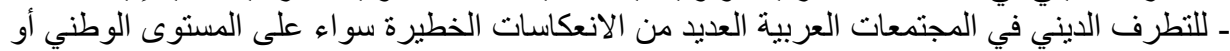

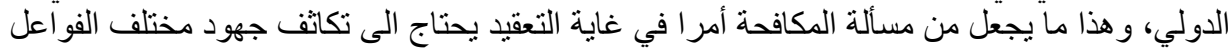

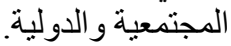

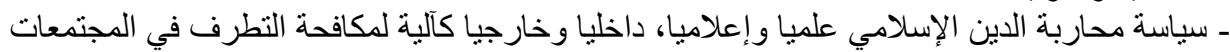

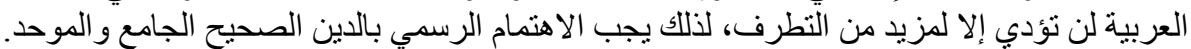

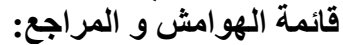

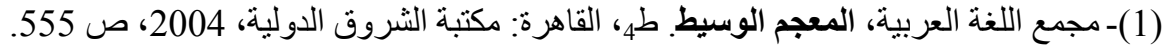
(2)Salah Al-Sawy, americans questions about islam : Post september 11. Egypt : Umm Al- Qura, 2002, P24. (3) أحمد مختار عمر، معجم اللغة العربية المعاصرة. المجلد الأول، القاهرة: عالم الكتب، 2008، ص :

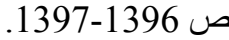

(4)- يوسف القرضاوي، الصحوة الإسلامية بين الجمود والتطرف. ط12، القاهرة: دار الثروق،

(5) Amos N Guiora, Freedom from Religion: Rights and National Security.2nd ED, New York : Oxford University Press, 2013, PP 10-11.

(6) Thomas A. Idinopulos,Brian Courtney Wilson, What Is Religion?:

Origins, Definitions, and Explanations. USA : Brill Academic Pub, 1998, P01. (7)- نو ال طارق إبر اهيم العبيدي، الجرائم الماسة بحرية التعبير عن الفكر. عمان: دار الحامد للنشر و

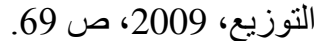
(8)- مصطفى عبد الرازق، الدين والوحي و الإسلام. القاهرة: مؤسسة هنداوي للنشر و التوزيع، 2012،

(9)Gulnar Hasanova, Fight with extremism and freedom of religion concerns. Azerbaijan, 2014, PP $02,09$. 


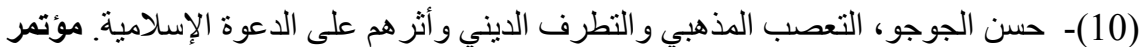

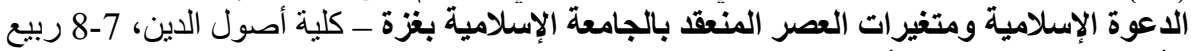

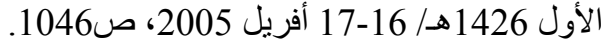
(11)- علي عبد الرحيم صالح، سيكوسولوجيا التطرف الايني بين الانغلاق الفكري و جذور الإرهاب.

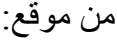
وجيكوسولوجيا التطرف الديني بين الانغلاق الفكري http://www.wasatyea.net/?q=ar/content/

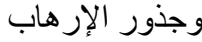
(12)- عزمي بشارة، في ما يسمى التطرف. مجلة سياسات عربية، العدد 14، ماي 2015، ص ص

(13)- المرجع نفسه، ص12. 12. لمزيد من المعلومات حول مفهوم التطرف الديني أنظر:

Vincent N. Parrillo, Encyclopedia of Social Problems,USA : Sage Publications, 2008 Volume 1, P773.

R. Scott Appleby,Atalia Omer,David Little, The Oxford Handbook of Religion, Conflict, and Peacebuilding. New York: Oxford University Press, 2015, P217.

$$
\begin{aligned}
& \text { (14)- يو سف وردانى، مداخل مكافحة النطرف بين الثباب في مصر .مجلة بدائل الصادرة عن مركز }
\end{aligned}
$$

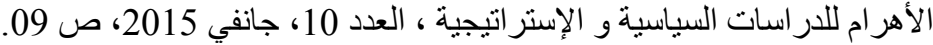

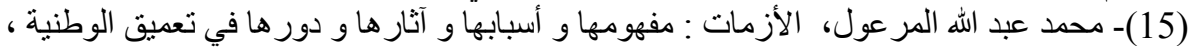

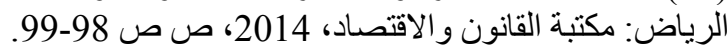

$$
\begin{aligned}
& \text { (16)- بلهول نسيم وآخرون، التطرف الايني. عمان: أمو اج للطباعة و النشر و التوزيع، 2014، ص ص التص }
\end{aligned}
$$

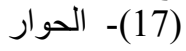

$$
\begin{aligned}
& \text { اليوم، التطرف الديني: المفهوم الرئيس و المفاهيم ذات الصلة. من موقع: }
\end{aligned}
$$

http://www.alhiwartoday.net/node/7149

(18)- عبد الو هاب الكيالي، موسوعة السياسة. طح، ج1،بيروت: المؤسسة العربية للار اسات و النشر،

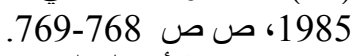

(19)- مؤسسة أعمال الموسوعة للنشر و التوزيع. الموسوعة العوبر العوبية العالمية. طح، المجلد 11،

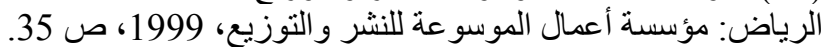

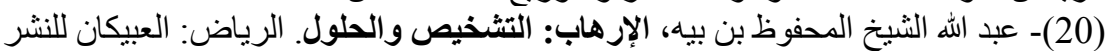

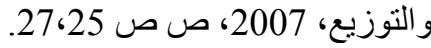

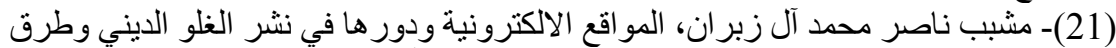

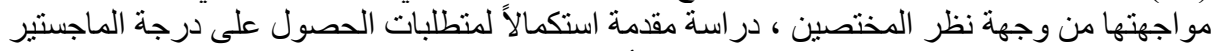

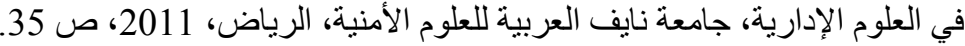

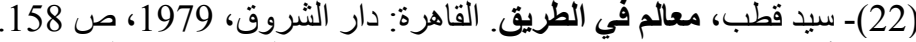

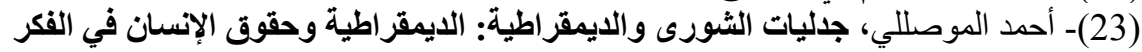

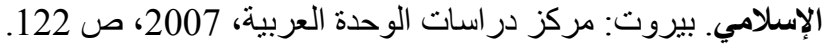

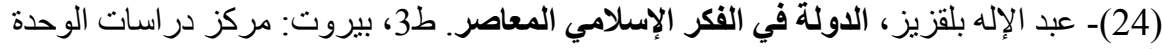

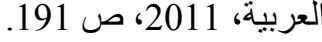

(25)- محمد قطب، العلمانيون والإسلام. القاهرة: دار الثروق، 1894، 1994، ص64. (26)- عبد الإله بلقزيز، ، المرجع السابق، ص ص صلإن 186-187. 
(27)- امحمد جبرون، "الإسلاميون في طور تحول: من الديمقر اطية الأداتية إلى الديمقر اطية الفلسفية

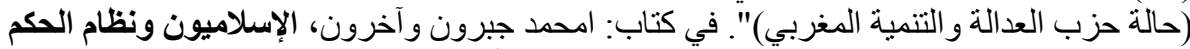

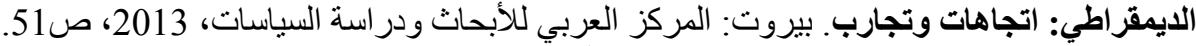

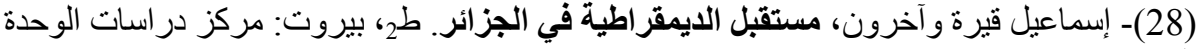

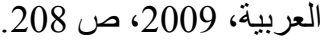

(29)- محمد أركون، قضايا في نقد العقل الديني: كيف نفهم الإسلام اليوم؟ بيروت: دار الطليعة

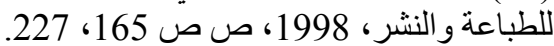

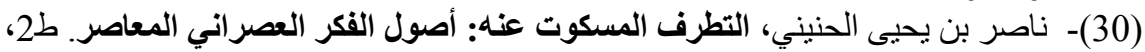

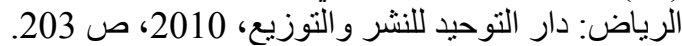
(31)- صلاح الصاوى، التطرف الديني: الرأي الآخر ، القاهرة ، الآفاق الدولية للإعلام، 1993، ص

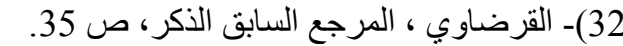

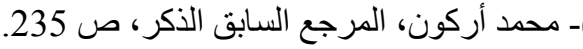

(34)- نجيب محفوظ ، حول التلين و التطرف. القاهرة: الدار المصرية اللبنانية، 1996، ص ص 57-

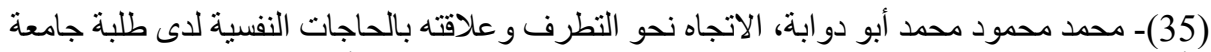
الأزهر بغزة. رسالة ماجيستير في كلية التربية بقسم علم النفس، جامعة الأزهر بغزة، فلسطين، 2012،

(36)- العياشي عنصر، العولمة و التطرف: نحو استكثاف علاقة ملتبسة. مجلة سياسات عربية، العدد

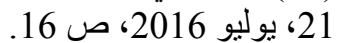

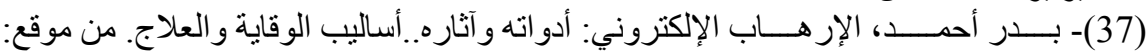

\&http://baathparty.sy/site/arabic/index.php?node=552\&cat=15369

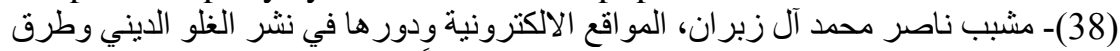

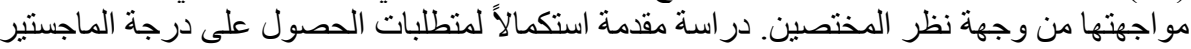

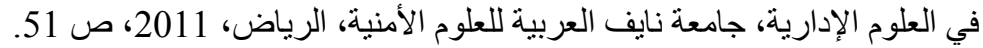

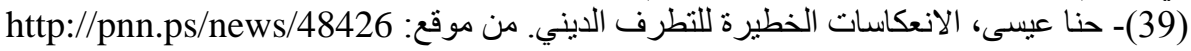

